\title{
ASSESSMENT OF SAMPLING AND CHEMICAL ANALYSIS OF WASTE PRINTED CIRCUIT BOARDS FROM WEEE: GOLD CONTENT DETERMINATION
}

\author{
Martina Laubertova ${ }^{1 *}$, Marcela Malindzakova ${ }^{2}$, Jarmila Trpcevska ${ }^{1}$, Nataša Gajic ${ }^{3}$ \\ ${ }^{1}$ Technical University of Kosice, Institute of Recycling Technology, Letna 9, \\ 04200 Kosice, Slovakia \\ ${ }^{2}$ Technical University of Kosice, BERG Faculty, Institute of Logistics and Transport, \\ Park Komenskeho 14, 040 00, Kosice, Slovakia \\ ${ }^{3}$ Innovation Center of the Faculty of Technology and Metallurgy in Belgrade Ltd., \\ University of Belgrade, Karnegijeva 4, 11120 Belgrade, Serbia
}

Received 31.05.2019

Accepted 26.06.2019

\begin{abstract}
Waste printed circuit boards (WPCBs) from discarded mobile phones and smartphones are considerably heterogeneous materials with a high gold content (approx. 490 grams per ton). The aim of our chemical analysis of samples of WPCBs was to determine the amounts of gold using open acid digestion and atomic absorption spectrometry (HR CS AAS). The test samples designated for chemical analysis must genuinely represent the bulk WPCBs from which they are taken. This study aimed to develop a correct sampling procedure to analyze the heterogeneous materials from printed circuit boards; explicitly concerning the influence of particle size on the precision of chemical analysis of WPCBs from discarded mobile phones. Chemical analysis of the representative sample of WPCBs with a grain size fraction of $\mathrm{d} \leq 200 \mu \mathrm{m}$ determined that the gold content was $475 \mathrm{~g} \cdot \mathrm{t}^{-1}$ with a low variation coefficient and low dispersion which indicates very high accuracy of the designed sampling procedure.
\end{abstract}

Keywords: WEEE; waste mobile phones; sampling; analysis; gold.

${ }^{*}$ Corresponding author: Martina Laubertová, martina.laubertova@tuke.sk 


\section{Introduction}

According to the literature [1], waste material from mobile phones as part of electronic waste (WEEE) is classified as hazardous waste, and should, therefore, be managed following the specific legislation. In recycling, elements such as copper and aluminum are recovered, as well as the precious metals gold, silver, platinum, and palladium, which can be recouped profitably from electronic waste. However, the high contents of precious metals (up to $400 \mathrm{~g}$ of gold per ton of waste) and base metals (up to $34 \mathrm{wt} . \%$ of copper) make this waste very valuable for recycling [2,3]. Statistics also indicate that in 2019, the number of mobile phone users will reach 4.68 billion in the world [4]. Precious metal ( $\mathrm{Ag}, \mathrm{Au}$ ) content has remained fairly constant with the shift from older mobile phones to newer smartphones [5] There is no decreasing trend in precious metals (PM) content in newer product types.

The success of treatment of e-scrap depends mostly on the quality of sampling and assaying. Professional sampling and analysis are the basis for proper material assessment. However, sampling is difficult for e-waste composition analysis due to the highly inhomogeneous nature of these materials, with large quantities and varieties of small components attached to WPCBs. Most sampling and assaying processes and technologies are still in-house developed. The general procedure in preparing samples from WPCBs involves crushing them into smaller sizes (less than 1-2 mm), which is followed by various techniques including magnetic, electrostatic, electrowinning, and selective dissolution in order to separate the components. WPCBs from mobile phones have higher (34.5\%) copper content compared to personal computers $(20 \%)[6,7]$. Sampling and assaying are necessary in order to determine the composition and content of precious metals in the flow of e-waste and to ensure that the optimum process is used to recover precious metals. All electronic scrap is sampled before entering the processing line. This sampling procedure is essential because the metal amounts determined in the analyzed waste material become the basis for the payment received by the supplier. The sampling facility contains a heat-hall for containers and unloading equipment for material from containers and big bags. An e-scrap shredder crushes the waste printed circuit boards which are delivered intact, and the material then passes through the stream sampler and is delivered to a storage facility where it is mixed before smelting [8].

We have recently described [9] the sampling procedure in the Kovohuty, a.s. Krompachy copperworks in Slovakia (Figure 1A). 


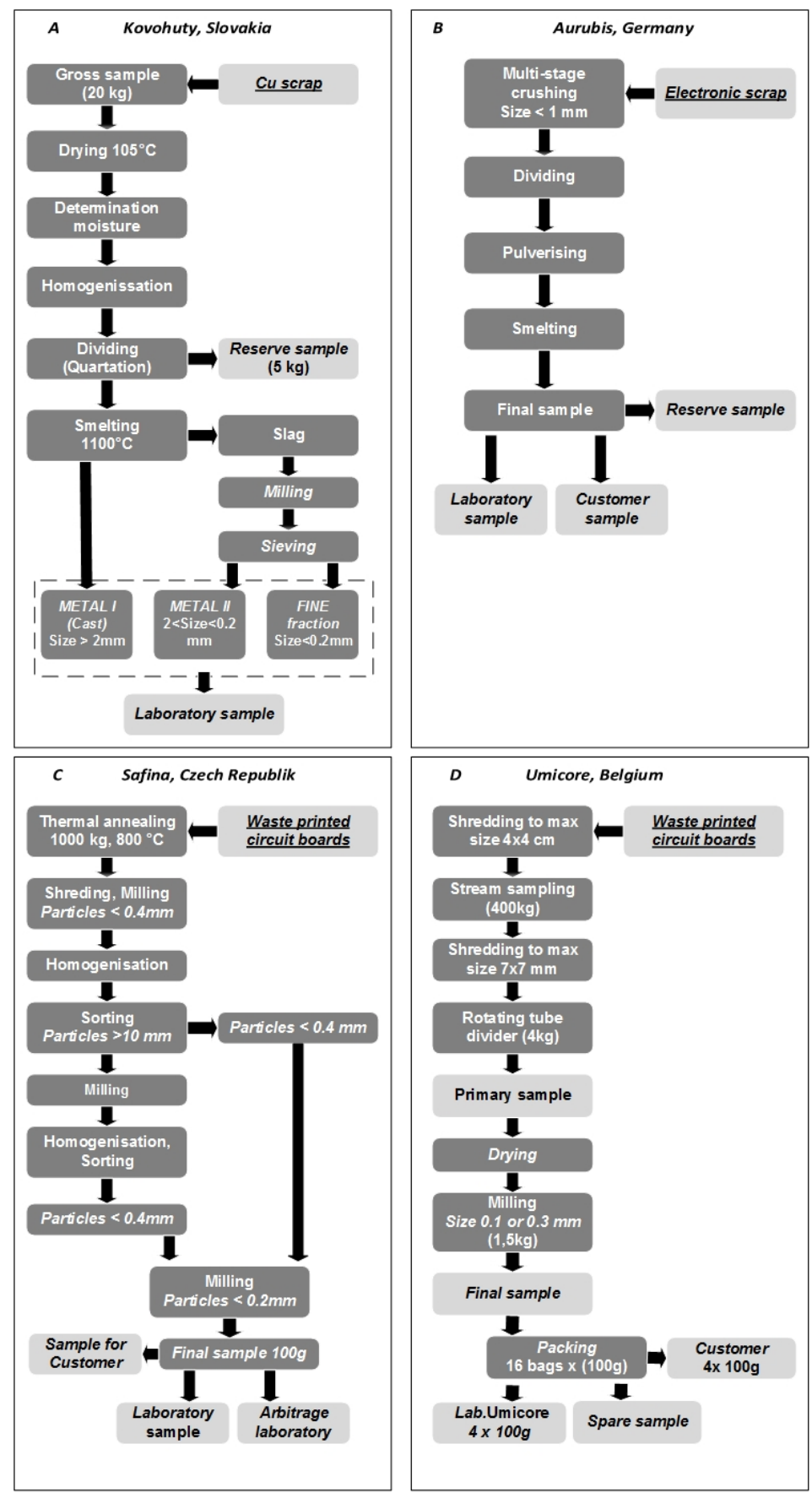

Fig. 1. A sampling at Kovohuty, Slovakia (A), Aurubis, Germany (B), Safina, Czech Republic $(C)$, and Umicore, Belgium (D). 
The sampling procedure in the SAFINA company in the Czech Republic [9] is shown in Figure 1C and can be described as follows. The precious metal-containing material is first pre-treated and subsequently homogenized into suitable batches for subsequent sampling. Using oxidative combustion or thermal annealing without the access of air within the annealing oven at a temperature of $850^{\circ} \mathrm{C}$, the material becomes devoid of all organic matter and moisture. After this treatment in the furnace, the material is crushed and ground in a special mill into a grain-size fraction of less than 0.4 $\mathrm{mm}$. This process is followed by sampling, where an analytical sample weighing about $100 \mathrm{~g}$ must represent the composition of the entire volume of the processed material, whether the volume consists of a few tons or just a few kilograms. The samples have a grain size of less than $0.2 \mathrm{~mm}$ and are prepared by milling the material on a vibrating disc grinder. Then after grinding, the material is screened and subsequently divided into eight equal portions of the same weight and the same composition. For the sampling of e-scrap in Boliden Rönnskär [10] even before arriving at Rönnskär, the e-scrap undergoes the pre-processing steps, namely in the form of dismantling and crushing. Glass, a certain amount of plastic, iron, and aluminum are separated at this stage because the precious metals such as copper, gold, and silver have the value for the smelter.

Umicore [11] does not grade individual boards itself but relies on its suppliers to do this, based on the physical composition of the boards and the value of the precious metals (Figure 1D). When the WPCBs are received, they use a sampling and assaying procedure for the identification of the exact content of precious, base, minor metals, and plastics contained in the shipment.

A sampling at Aurubis [12] is shown in Figure 1B. Multi-stage crushing and dividing to $<1 \mathrm{~mm}$, pulverizing and smelting are used for the preparation of the final sample. Due to the inconsistent final sample treatment as a result of modifications to the electronic waste, the experimental part of this work focuses on studying the influence of sample granularity on the determination of gold content in WPCBs from mobile phones. Complex raw materials need specific treatment in sampling. Complex materials are less constant in quality, so a higher quantity of the same lot must be analyzed: e.g., $\mathrm{Cu}$ granules: $300 \mathrm{~kg} / \mathrm{lot}$ instead of $80 \mathrm{~kg} / \mathrm{lot}$ [10]. In their study, [5] analyzed the metal content of WPCBs in mobile phones, smartphones, and internet routers using 3-4 g sample weights for analyses. A combined batch of WPCBs from each product type was milled into a 2-3 $\mathrm{mm}$ fraction and homogenized, and then three samples were taken, each milled further with a cryo-centrifugal milling device and then subsequently analyzed for the metal content. Leaching and analyses were performed according to the ALS Scandinavia standard analysis [13]. In 1999, at the request of the electronics industry, ALS Scandinavia developed an analytical method for the determination of a broader range of metals and other elements in circuit boards. The price for the analysis of sample-type electronic waste is 486 Euro for determination of $\mathrm{Ag}, \mathrm{As}, \mathrm{Au}, \mathrm{Be}, \mathrm{Cd}$, $\mathrm{Cr}, \mathrm{Cu}, \mathrm{Hg}, \mathrm{Ni}, \mathrm{Pb}, \mathrm{Pd}, \mathrm{Pt}, \mathrm{Sb}, \mathrm{Sn}$, and $\mathrm{Zn}$. For determination of metals content, the ICP-SFMS analytical method is used. In their study [2] analyzed WPCBs from mobile handsets after roasting and acid digestion, using atomic absorption spectroscopy. The content of gold and silver in the PCBs was found to be in the range $0.009-0.017 \%$ and $0.25-0.79 \%$ by weight respectively. The copper and nickel contents in four representative samples of WPCBs after open conventional digestion were determined using the AAS method in two grain-size fractions, less than $1250 \mu \mathrm{m}$ and less than 1000 
$\mu \mathrm{m}$. The results were statistically evaluated in the literature [14], and [15]. The contents of copper, lead, nickel, and zinc in WPCBs from discarded mobile phones were determined. Mixtures of hydrogen peroxide, aqua regia, and hydrofluoric acid were applied to test sample digestion. Closed- and open-vessel wet digestion with or without heating, as well as microwave-assisted digestion, was carried out [16]. This paper aims to study the influence of different grain-size samples on the accuracy of chemical analysis for determining the Au content in WPCBs from electronic scrap.

\section{Experimental}

\section{Materials and methods}

Testing of the sampling procedure

The input material used in this work was collected from different types of discarded push-button mobile phones, as demonstrated in the literature [9, 17]. Approximately $10.30 \mathrm{~kg}$ of collected mobile phones were used for the experiment. Removed printed circuit boards were used for the experiment $(4.3 \mathrm{~kg})$. The crushing operation was carried out in a hammer crusher (type 22-5s3964, Weber) down to a fraction size of $(\mathrm{d} \leq 8 \mathrm{~mm})$, which should be representative of this bulk material (WPCBs). The sample (1000 g) was obtained by hand quartering and was then divided three times with a divider (type RV-01 / 2007, Spiscol Ltd.). Magnetic separation was then performed to remove the magnetic fragments from the sample using a laboratory magnetic separator (SPUC 450/ 2014, UNIKASSET, Ltd.). Figure 2A shows the mass of the magnetic fraction and grain size fraction for eight samples (AH1-AH8). The weight of the magnetic fraction of the individual samples after magnetic separation was standardized to an average of $30.33 \%$ by weight for each of the magnetic fractions in the sample. The representative samples were milled into fractions with a size of less than $1 \mathrm{~mm}$ in a hammer mill (type Hamilton Mich 49419) and subsequently sieved into the four grain fraction sizes: $(d \leq 2000 \mu \mathrm{m}) ;(1000 \geq d \geq 200 \mu \mathrm{m}) ;(\mathrm{d} \leq 400 \mu \mathrm{m})$ and $(\mathrm{d} \leq 200$ $\mu \mathrm{m})$ using an analytical vibratory sieve shaker (AS 450 control). The procedure of sampling WPCBs with the first operations of crushing, homogenization, dividing, magnetic separation, and milling was made. The $1 \mathrm{~g}$ test samples taken from each fraction were then analyzed in order to determine the amounts of gold using atomic absorption spectrometry (AAS) (ICE 3000 Series, Thermo Scientific). In order to check the influence of WPCB sample granularity on the accuracy of the chemical analysis, the samples were also subjected to light microscopy observation using a Dino-Lite ProAM413T instrument.

Chemical characterization

Firstly, eight $1 \mathrm{~g}$ samples of each grain-size fraction were weighed on an EXPLORER analytical balance with a weighing error of $0.0001 \mathrm{~g}$. Then open acid digestion at the boiling point of the solution was carried out with a mixture of $30 \mathrm{~cm}^{3}$ $\mathrm{HCl}+10 \mathrm{~cm}^{3} \mathrm{HNO}_{3}$. Analytical grade purity commercial nitric acid $(65 \%)$ and hydrochloric acid $(36 \%)$ were used for sample digestion. After digestion, the mixtures were filtered, and in the final solutions, the content of $\mathrm{Au}$ was determined. This was done using high-resolution continuum-source atomic absorption spectrometry (HR CS AAS) using an AA Spectrometer (Thermo Scientific ICE 3000 Series) at $242.9 \mathrm{~nm}$ with flame acetylene air. The averages from triplicate samples in the solutions after dissolution were analyzed. Volumetric flasks can visually show the different intensities 
of the staining solution, which suggests different contents of other metals present $(\mathrm{Ni}$, $\mathrm{Cu})[15]$.

\section{Statistical approach}

In Figure 3A [18] there is a so-called box chart, which in this particular case displays the position of the center value for a given data set. The upper and the lower quartiles show the box plot representing $50 \%$ of the whole selection. If we assume symmetry, then within those limits there are parts which restrict the range of the forecast data. All data found outside the lower and upper bounds are extreme values and can be shown separately. In terms of the design aspect, the box chart may differ between various usages. Within the rectangle of the box chart, the upper and lower lines represent the upper and lower quartiles of the data set, and the middle vertical divider represents the median. Based on the size of the ordered values, in this case, three vertical lines are dividing the measured data into four equal segments. The width of the box chart represents the so-called interquartile range. Each slightly-outlying value represents 1.5 times the interquartile range from the $25 \%$ quartile on the left and the $75 \%$ quartile on the right. Marks represent the arithmetical averages of all measured data within the box chart.

\section{Results and discussion}
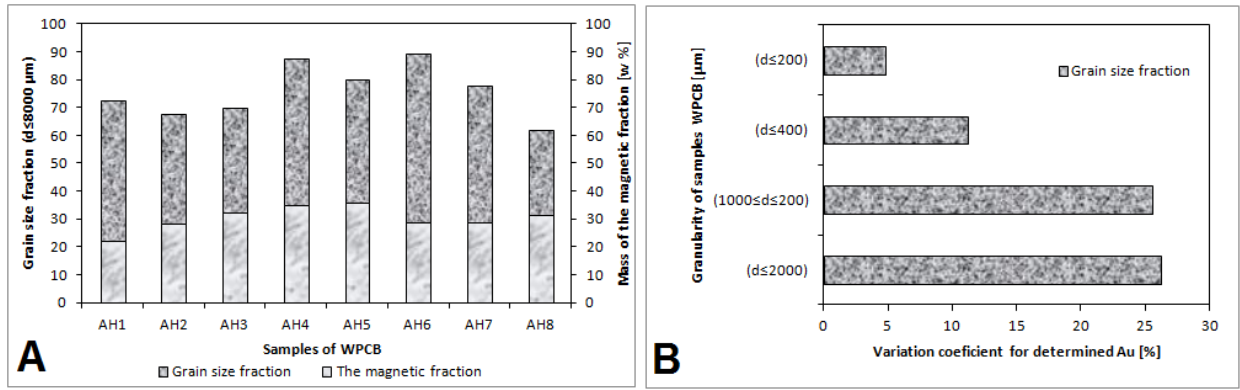

Fig. 2. A - Mass of the magnetic fraction in the individual samples, B - Influence of WPCBs sample granularity on the accuracy of chemical analysis.

The results of the chemical analysis to determine the Au content (in $g \cdot t^{-1}$ ) in the four grain-size fraction samples of WPCBs are shown in Table.1. The individual grainsize fractions were obtained and the arithmetical mean value $x_{p}$, standard deviation $S D$, dispersion $S D^{2}$ and variation coefficient $V_{x}$ were calculated for each fraction. Statistical data representing the results from chemical analysis for each fraction is shown in Table 2. 
Table 1. Analytical results of gold determination for each sample fraction.

\begin{tabular}{lcccc}
\hline $\begin{array}{l}\text { Grain-size } \\
\text { fraction } \\
{[\mu \mathrm{m}]}\end{array}$ & $(\mathrm{d} \leq 2000)$ & $(1000 \geq \mathrm{d} \geq 200)$ & $(\mathrm{d} \leq 400)$ & $(\mathrm{d} \leq 200)$ \\
\hline & \multicolumn{4}{c}{$\left.\mathrm{Au} \mathrm{[ \textrm {g } \mathrm { t } ^ { - 1 } ]}\right)$} \\
\hline samples & $\mathrm{AH} 9-\mathrm{AH} 16$ & $\mathrm{AH} 17-\mathrm{AH} 24$ & $\mathrm{AH} 25-\mathrm{AH} 32$ & $\mathrm{AH} 33-\mathrm{AH} 40$ \\
1 & 361.62 & 150 & 442.00 & 480 \\
2 & 404.0 & 120 & 460.86 & 480 \\
3 & 396.34 & 110 & 454.68 & 490 \\
4 & 256.94 & 120 & 544.67 & 490 \\
5 & 237.95 & 180 & 460.69 & 450 \\
6 & 543.04 & 180 & 454.72 & 450 \\
7 & 447.65 & 180 & 536.94 & 510 \\
8 & 453.91 & 90 & 587.94 & 450 \\
\hline
\end{tabular}

Table 2. Comparison of statistical data for different sample fractions.

\begin{tabular}{lcccc}
\hline \multirow{2}{*}{ Statistical data } & Grain-size fraction $(\mu \mathrm{m})$ for measured values of $\mathrm{Au}$ \\
& & & & \\
& $(\mathrm{d} \leq 2000)$ & $(1000 \geq \mathrm{d} \geq 200)$ & $(\mathrm{d} \leq 400)$ & $(\mathrm{d} \leq 200)$ \\
\hline Arithmetical mean $-\mathrm{x}_{\mathrm{p}}\left[\mathrm{g} \mathrm{t}^{-1}\right]$ & 387.75 & 141.25 & 492.81 & 475 \\
Dispersion - $\mathrm{SD}^{2}$ & 10376.79 & 1298.21 & 3032.20 & 514.29 \\
Standard Deviation $-\mathrm{SD}$ & 101.87 & 36.03 & 55.07 & 22.68 \\
Variation Coefficient $-\mathrm{V}_{\mathrm{x}}[\%]$ & 26.27 & 25.51 & 11.17 & 4.77 \\
\hline
\end{tabular}

The variation coefficient determines the accuracy of the measurement. The measurements are accurate as long as the value of the variation coefficient is within the interval $\langle 0-30\rangle$, , which is in turn, represented in Figure 3(B-E). All four Figures indicate that there is no extreme value of the measured gold contents. Figure 3B shows that the grain size of the gold in the interval $(1000 \geq \mathrm{d} \geq 200)$ has the lowest average value. From Figure 3B and Figure 3C, it follows that the higher the granularity, the less scattered the measured values are. Figure $3 \mathrm{E}$ shows that the measured gold values are evenly distributed, and the grain variation coefficient has the smallest value at the lowest grain size. Figure 2C illustrates that the higher the gold granularity, the higher the coefficient of variation. As the values of the variation coefficient indicate, the measurements for all grain-size fractions are accurate. The variation coefficient of the measured values of gold with grain size $\mathrm{d} \leq 200$ has the lowest value, which means that the measurements are accurate with a percentage of 4.77. It can be stated that the larger the grain size, the less accurate the measurement Figure 3C. 

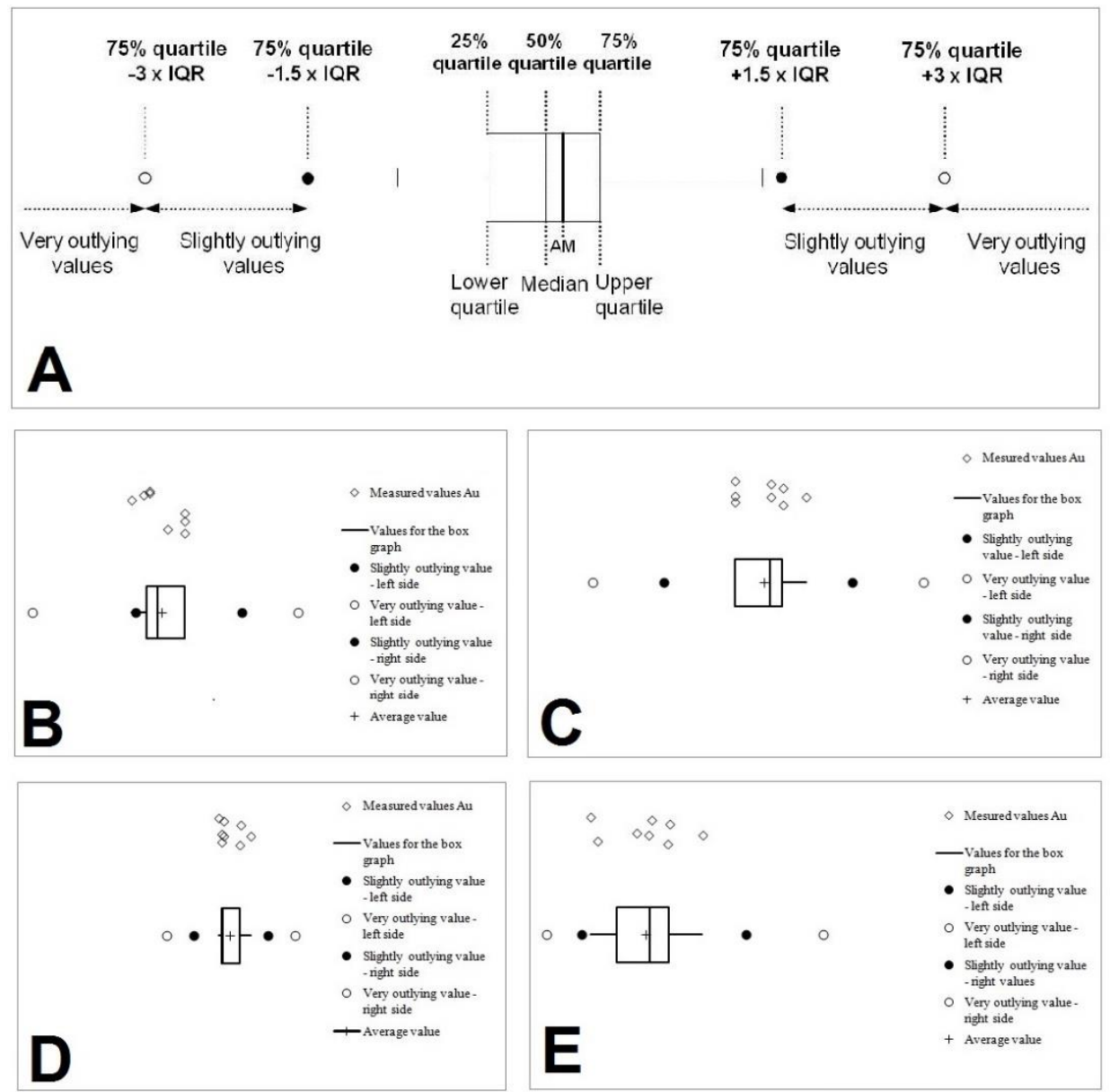

Fig. 3. (A) -Box graph with outlying values (B-E)-Measured values of Au content represented in a box plot for four grain-size fraction $B(1000 \geq d \geq 200 \mu \mathrm{m})$, $C(d \leq 2000 \mu \mathrm{m}), D(d \leq 400 \mu \mathrm{m})$ and $E(d \leq 200 \mu \mathrm{m}), N=8$. 

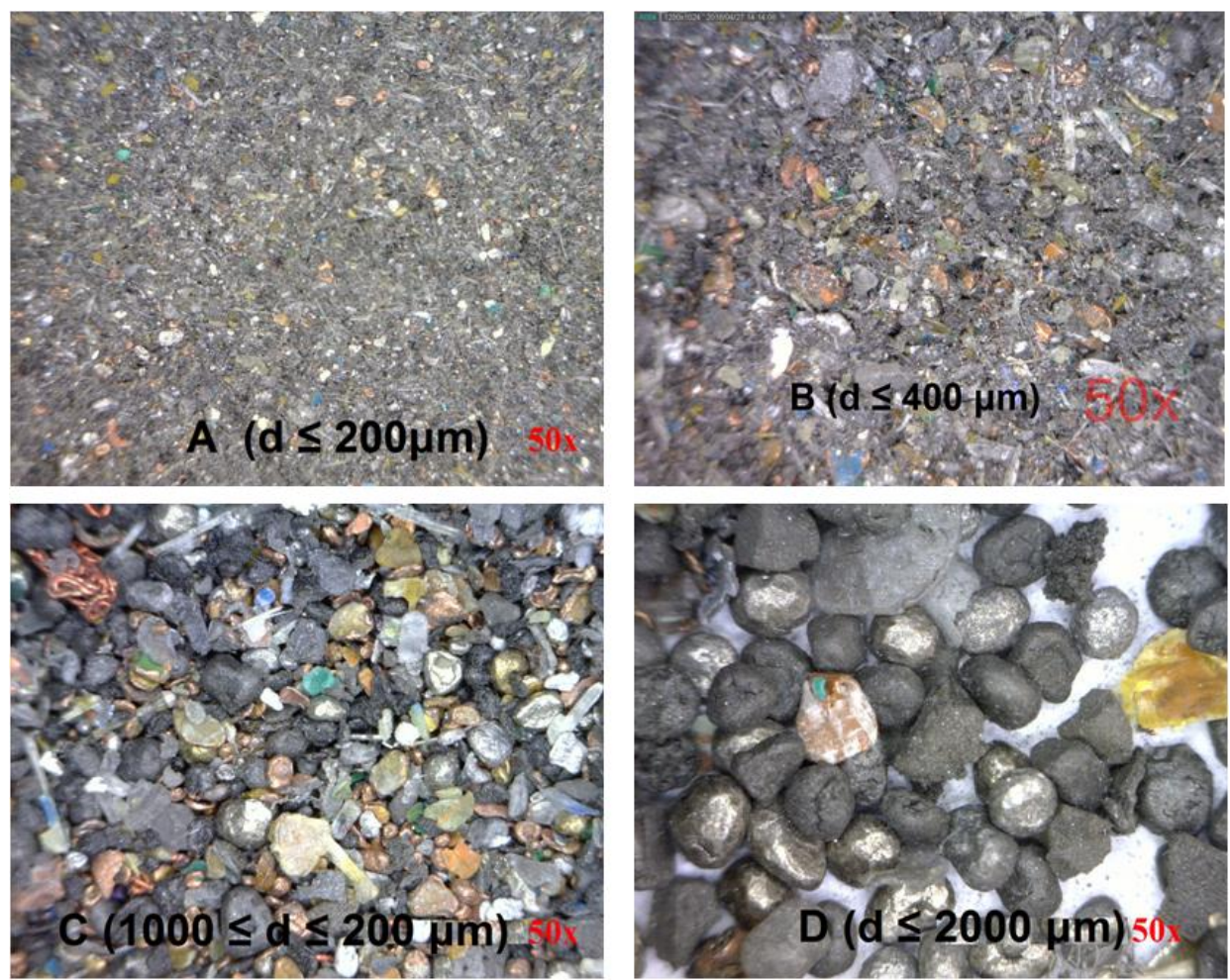

Fig. 4. (A-D) Light microscope images of four grain-size fractions of WPCBs.

Figure 4 (A-D) shows the influence of WPCB sample granularity on the accuracy of the chemical analysis. The lower the grain size of a representative sample for chemical analysis indicate on the higher the accuracy in determining the precious metal content in the sample. Figure 5 shows the designed flowchart for WPCB sampling used in this study. WPCBs (10\% gross sample) were removed from all collected button-type phones. Accumulators and plastic covers were discarded from the gross sample. The WPCBs were mechanically processed by crushing and milling and subsequently homogenized. Representative samples were obtained by dividing (quartering) the laboratory material. The samples were dissolved using open acid digestion, then subjected to chemical analysis (HR CS AAS method) to determine Au contents. 


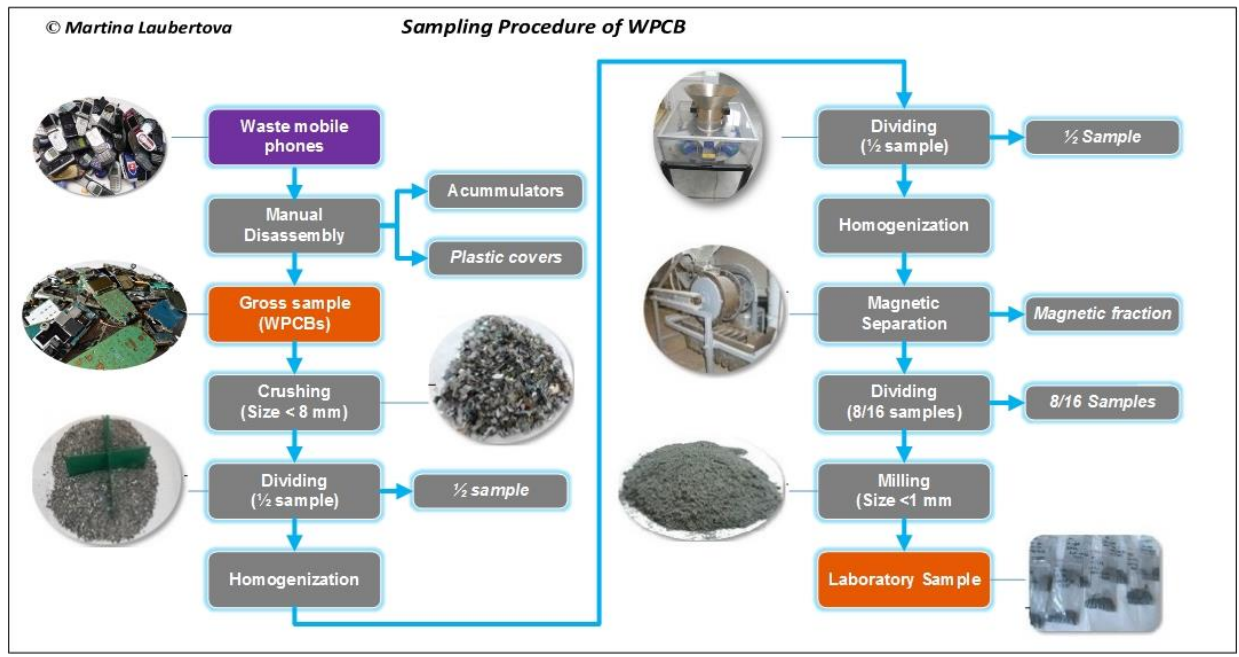

Fig. 5. Final sampling procedure flowchart for WPCBs from mobile phones.

\section{Conclusion}

The influence of different grain-size samples on the accuracy of chemical analysis for determining the Au content in WPCBs from mobile phones was studied. The statistically-evaluated results of the analysis revealed that the granularity of the representative sample had the most significant impact on the accuracy of the sampling procedure in order to determine $\mathrm{Au}$ content in waste printed circuit boards. In conclusion, it can be stated that the lower the granularity, the lower the variation coefficient. The results were subject to reduced error, which means that better accuracy was achieved. The gold content determined in a WPCB representative sample (grain size of $d \leq 200 \mu \mathrm{m}$ ) with Variation Coefficient of $4.77 \%$ indicates a very high accuracy of the sampling procedure. The statistical design applied indicates that valuable information about the quality of the waste sampling procedure and chemical analysis can be obtained from the presented eight representative samples for each grain-size fraction. The WPCB sampling procedure and chemical analysis used here are reasonably representative of discarded mobile phones in a single lot, and the uncertainty of the data is reasonably low. With comparison to other mentioned methods of PCB sampling methodology, this designed methodology has the advantage of being very easy, fast, and low energy consumption. 


\section{Acknowledgments}

This work was supported by the Ministry for Education of the Slovak Republic through grants VEGA [1/0442/17], VEGA [1/0631/17] and KEGA [017TUKE-4/2019].

\section{References}

[1] European Waste Catalogue and Hazardous Waste List, http://www.nwcpo.ie/forms/EWC_code_book.pdf Accessed 31 May 2019.

[2] M. C. Vats, and S. K. Singh: Waste Management, 45 (2015) 280-288.

[3] Sarath, P., Sateesh Bonda, Smita Mohanty, and Sanjay K. Nayak: Waste Management, 46 (2015) 536-545.

[4] Number of mobile phone users worldwide from 2013 to 2019 (in billions), https://www.statista.com/statistics/274774/forecast-of-mobile-phone-usersworldwide/ Accessed 31 May 2019.

[5] Holgersson, Stellan, Britt-Marie Steenari, Max Björkman, and Klas Cullbrand: Resour, Conserv Recycl, 133 (2018) 300-308.

[6] Veglio, F., Birloaga, I., Waste Electrical and Electronic Equipment Recycling, Eds, first., Elsevier, United Kingdom , 2018, 406 pp.

[7] A. Khaliq, M. Rhamdhani, G. Brooks, and S. Masood: Resources, 3 (2014) 152179.

[8] Boliden NO.1 in E-recycling, https://www.boliden.com/globalassets/investorrelations/reports-and-presentations/capital-markets-day/2012/cmd/11-bolidenno-1-in-recycling.pdf Accessed 31 May 2019.

[9] M. Laubertova, M. Malindzakova, A. Rosova, and J. Trpcevska: Przemysl Chemiczny, 95 (2016) 1390-1394.

[10] R. Sundqvist, E-Scrap Fundamentals, 2012, 1-16 https://www.boliden.com/globalassets/investor-relations/reports-andpresentations/capital-markets-day/2012/cmd/2-e-scrap-fundamentals-rogersundqvist-general-manager-boliden-ronnskar.pdf Accessed 31 May 2019.

[11] Weighing and sampling, Umicore, http://pmr.umicore.com/en/recyclables/spentindustrial-catalysts/weighing-and-sampling/ Accessed 31 May 2019.

[12] Recycling Aurubis, https://www.aurubis.com/binaries/content/assets/aurubisen/dateien/product-documents/recycling-brochure_2013_eng_doppelseitig.pdf Accessed 31 May 2019.

[13] ALS Scandinavia, Electrical and Electronic Equipment, Umweltbundesamt, http://www.umweltbundesamt.de/en/topics/waste-resources/productstewardship-waste-management/electrical-electronic-waste/electrical-electronicequipment-act Accessed 31 May 2019.

[14] M. Laubertova, J. Trpcevska, W. Zorawsky, E. Smincakova, J. Piroskova, Sampling Procedure of Printed Circuit Boards from Discarded Mobile Phones, VII International Metallurgical Congress, Ohrid, Macedonia, 2016, 3-7.

[15] M. Laubertova, J. Trpcevska, M. Malindzakova: Pol J Environ Stud, 27 (2018) 1593-1599.

[16] V. Mičková, S. Ružičková, D. Remeteiová, M. Laubertová, and M. Dorková: Chemical Papers, 72 (2018) 1231-1238. 
[17] A. Hercko, The Influence of Grain Size of a Representative Sample on the Accuracy of Electronic Waste Sampling, 2017, 73 pp.

[18] P. Hebak, Statistical Thinking and Data Analysis Tools, Prague, 2011, 877 pp.

\section{(c) (i) Creative Commons License}

This work is licensed under a Creative Commons Attribution 4.0 International License. 